\title{
Rancang Bangun Mesin Poles Piringan Tunggal (Single Disc) Untuk Proses Metalografi
}

\author{
Ferry Budhi Susetyo $^{1 *}$, Muhamad Muslih ${ }^{1}$, Muhamad Agil Febrianto ${ }^{1}$, Basori \\ ${ }^{1}$ Program Studi Teknik Mesin, Fakultas Teknik, Universitas Negeri Jakarta, 13220 \\ ${ }^{2}$ Program Studi Teknik Mesin, Fakultas Teknik dan Sains, Universitas Nasional 12520 \\ *Korespondesi penulis: fbudhi@unj.ac.id
}

(Received: 12-02-2021; Revised: 29-03-2021; Accepted: 16-04-2021)

\begin{abstract}
A polishing machine for the metallographic process is the equipment used to carry out surface preparations. The smooth surface is expected so that after etching it can be seen the micro or macrostructure of a material being studied with the aid of a microscope. In this research, we design and manufacture polishing machines. The main materials used in the process of designing this polishing machine are an electric motor (AC), carbon steel, cables, contactors, stainless steel plates, pushbuttons, emergency buttons, potentiometers, $v$ belts, pulleys, bearings, hoses, and shafts. This method of the research process begins with calculating the diameter of the follower pulley, then continues with size planning, drawing work, making simple electrical wiring drawings, manufacturing components, and assembling and testing. This polishing machine for the metallographic process has been designed as a disk rotating speed of $600 \mathrm{rpm}$, an electric motor of $135 \mathrm{~W}$ with a voltage of $220 \mathrm{~V}$, and also has a plumbing system. From the test results of polishing machine for metallography, the desired polishing results were obtained.
\end{abstract}

Keywords: polishing machine, surface polishing, designing, fabrication, metallography.

\begin{abstract}
Abstrak. Mesin poles untuk proses metalografi adalah alat yang digunakan untuk para peneliti melakukan preparasi permukaan. Permukaan halus yang diharapkan sehingga setelah di etsa dapat dilihat struktur mikro atau makro dari suatu material yang diteliti dengan bantuan mikroskop. Dalam penelitian ini, kami merancang dan membuat mesin poles. Bahan utama yang digunakan dalam proses perancangan mesin poles ini yaitu motor listrik AC, besi siku, kabel, kontaktor, plat stainless, tombol on/off, tombol emergency, potensiometer, $v$ belt, pulley, bearing, selang, poros dan piringan baja karbon. Metode perancangan dan pembuatan mesin poles untuk proses metalografi ini diawali dengan perhitungan diameter pulley pengikut, kemudian dilanjutkan dengan perencanaan ukuran, membuat gambar kerja, pembuatan gambar wiring kelistrikan sederhana, pembuatan komponen dan perakitan serta uji coba. Mesin poles untuk proses metalografi yang telah dirancang ini memiliki kecepatan putar piringan sebesar $600 \mathrm{rpm}$, motor listrik sebesar $135 \mathrm{~W}$ dengan tegangan $220 \mathrm{~V}$, dan juga mempunyai sistem saluran air. Dari hasil pengujian mesin poles untuk metalografi didapatkan hasil polesan sesuai yang diinginkan.
\end{abstract}

Kata kunci: mesin poles, pemolesan permukaan, perancangan, pembuatan, metalografi.

\section{LATAR BELAKANG}

Perkembangan ilmu pengetahuan serta teknologi saat ini menghasilkan dampak yang begitu massive untuk dunia industri, terutama industri pada bidang otomotif dan permesinan. Dimana saat ini industri otomotif merupakan industri utama di Indonesia [1]. Dalam industri, rekayasa material merupakan hal yang utama ketika melakukan perancangan dari pemesinan maupun otomotif. Dalam rekayasa material, pengamatan objek atau sampel hasil rekayasa mutlak diperlukan untuk melihat struktur mikro yang terbentuk. Sehingga diperlukan satu proses yang dinamakan metalografi. Sangat banyak penelitian yang telah menggunakan metode ini $[2,3]$.

Ada beberapa tahapan pada saat ingin melakukan proses metalografi yaitu adalah pemotongan, pembingkaian, penggerindaan, pemolesan, pengetsaan, setelah itu baru pengamatan menggunakan 
mikroskop optik. Untuk dapat dilakukan pengamatan dengan mikroskop optik maka permukaan spesimen harus benar-benar halus serta rata [4].

Mesin poles adalah salah satu alat yang bekerja menggunakan energi listrik dan amplas sebagai pengikis spesimen [5]. Prinsip kerja mesin poles adalah memutar piringan abrasif dengan motor listrik, lalu spesimen disentuhkan ke piringan abrasif yang berputar, sehingga menghasilkan putaran yang dapat mengikis permukaan benda menjadi lebih halus dari semula [6]. Mesin poles terdiri dari beberapa komponen penyusun, seperti motor listrik, dudukan motor, shaft, piringan amplas, pulley, belt, serta sirkulasi air.

Dalam penelitian tidak selalu mesin pendukung harus dibeli, ada kalanya mesin dibuat secara mandiri sehingga spesifikasi mesin seperti daya listrik dapat di tentukan sesuai yang diinginkan. Melalui suatu kegiatan rancang bangun, hal ini dapat diwujudkan [7-9]. Begitu banyak penelitian yang telah membuat mesin poles, namun motor listrik yang digunakan masih terlalu besar (3/4HP) $[3,5]$. Untuk itu dalam penelitian ini akan dibuat mesin poles single disc dengan menggunakan daya motor $135 \mathrm{~W}(0,18 \mathrm{HP})$ agar hemat energi.

\section{METODOLOGI}

Proses rancang bangun mesin poles untuk proses metalografi ini dilaksanakan dengan dua tahap. Tahap pertama yaitu proses perancangan dan tahap kedua yaitu proses pembuatan serta uji coba. Dua tahap ini dilakukan pada bulan Juni sampai dengan Desember 2020. Lokasi rancang bangun mesin poles ini bertempat di laboratorium Otomotif Teknik Mesin Universitas Negeri Jakarta. Lebih lengkap mengenai proses rancang bangun mesin poles dapat dilihat pada gambar 1.

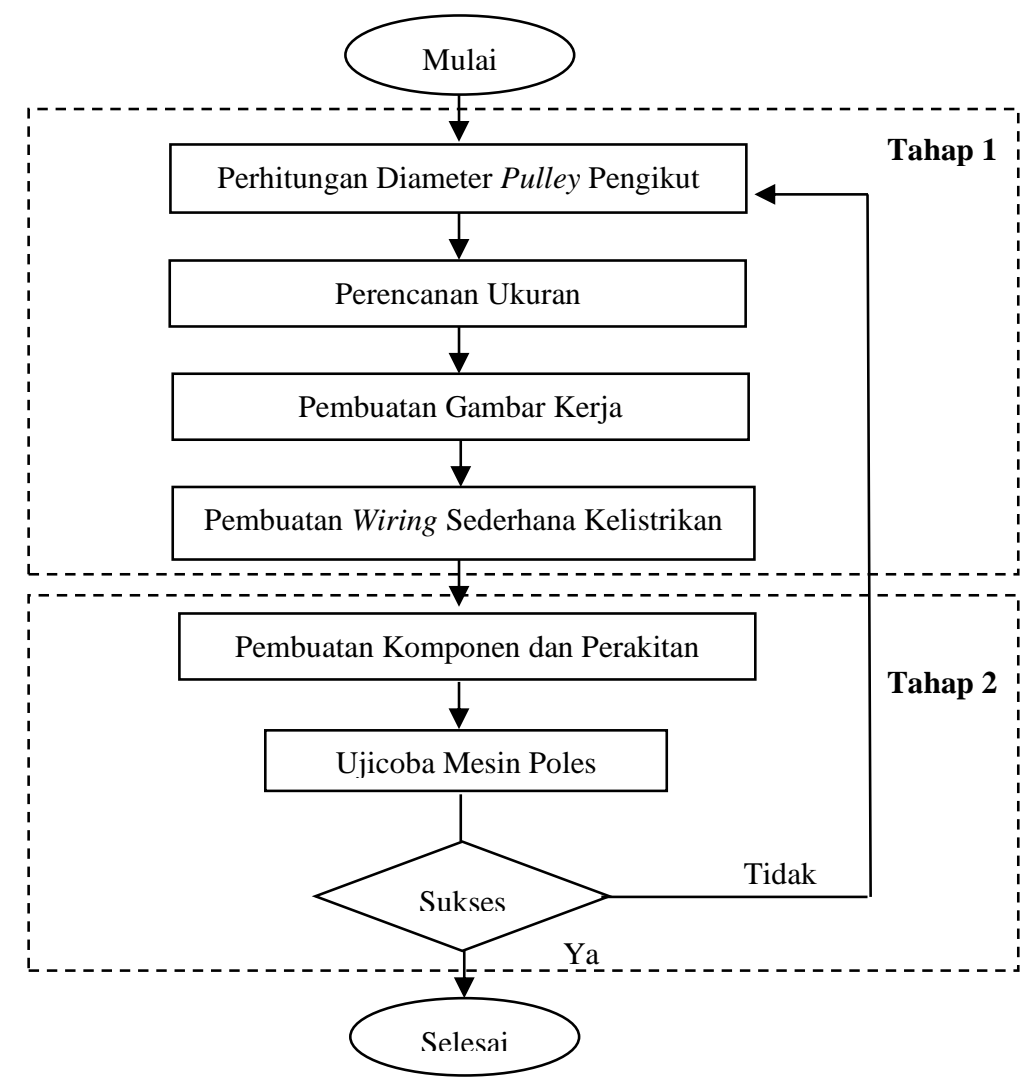

GAMBAR 1. Diagram alur penelitian.

Pada tahap 1 akan dilakukan perhitungan diameter pulley pengikut, perencanaan ukuran lalu dilanjutkan dengan pembuatan gambar kerja, dan pembuatan gambar wiring kelistrikan sederhana. Perhitungan diameter pulley pengikut menggunakan rumus sebagai berikut [10].

$$
\frac{N_{2}}{N_{1}}=\frac{D_{1}}{D_{2}}
$$


Setelah ditentukan diameter pulley pengikut, kemudian ditentukan perencanaan ukuran. Perencanaan ukuran dari mesin poles dimaksudkan untuk mengetahui berapa dimensi PxLxT dari rancangan mesin poles yang akan dibuat. Setelah ditentukan berapa dimensi rancangan mesin poles lalu dilanjutkan dengan pembuatan gambar kerja. Pada pembuatan gambar kerja ini, akan dibuat gambar kerja dengan detail dan lengkap dengan ukuran. Setelah selesai kemudian dilanjutkan dengan pembuatan gambar wiring kelistrikan. Pembuatan gambar wiring kelistrikan ini dibuat dengan sederhana, sehingga mudah difahami.

Selanjutnya pada tahap 2 akan dilakukan proses pembuatan komponen. Proses pembuatan dan perakitan komponen mesin poles meliputi pengukuran, pemotongan, penyambungan (las), pengeboran, penekukan, pengeboran dan pemasangan rivet. Proses-proses ini dilakukan dengan berdasarkan gambar kerja yang telah dibuat, sehingga produk akhir mesin poles sesuai dengan rancangan yang telah dibuat. Langkah terakhir pada penelitian ini yaitu uji coba mesin poles yang telah selesai dibuat. Ujicoba ini dilakukan pada spesimen dengan jenis alumunium menggunakan dua jenis amplas.

\section{HASIL DAN PEMBAHASAN}

Pada bagian ini akan dilakukan pembahasan dari proses rancang bangun mesin poles yang telah di kerjakan.

\section{Perhitungan Diameter Pulley Pengikut}

Perhitungan ini bertujuan untuk mengetahui seberapa besar diameter pulley pengikut yang digunakan untuk mereduksi putaran $\left(\mathrm{N}_{2}\right)$ hingga $600 \mathrm{rpm}$. Mesin poles ini menggunakan motor listrik dengan daya sebesar $135 \mathrm{~W}(0.18 \mathrm{HP})$, tegangan $220 \mathrm{~V}$ dan putaran $\left(\mathrm{N}_{1}\right)$ sebesar $1800 \mathrm{rpm}$. Diketahui diameter pulley penggerak $\left(D_{1}\right)=100 \mathrm{~mm}$ Dengan subtitusi ke dalam persamaan (1), maka didapatkan hasil diameter pada pulley pengikut $\left(\mathrm{D}_{2}\right)$ adalah $300 \mathrm{~mm}$.

\section{Perencanaan Ukuran}

Setelah ditentukan diameter pulley pengikut, maka dapat dilakukan perencanaan ukuran. Pada perencanaan ukuran akan dirancang dimensi dari mesin poles. Mesin poles akan dibuat dengan dimensi $500 \times 700 \times 245 \mathrm{~mm}$. Dimensi ini merupakan dimensi terluar dari mesin poles yang akan dibuat.

\section{Pembuatan Gambar Kerja}

Setelah didapatkan dimesi dari mesin poles kemudian dilanjutkan dengan pembuatan gambar kerja. Pada pembuatan gambar kerja mesin poles, drafter harus memperhatikan berbagai hal diantaranya adalah bahan yang akan digunakan serta proses pembuatan.

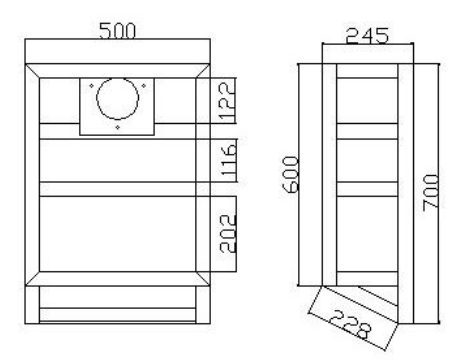

(a)

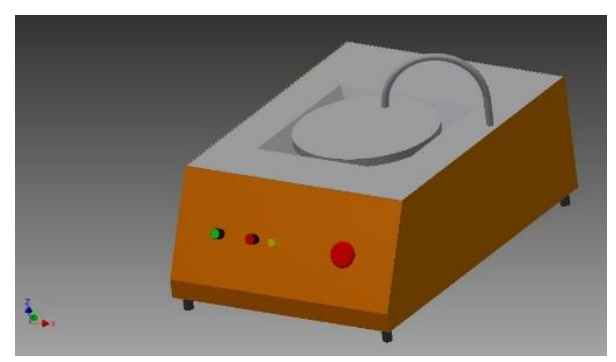

(b)

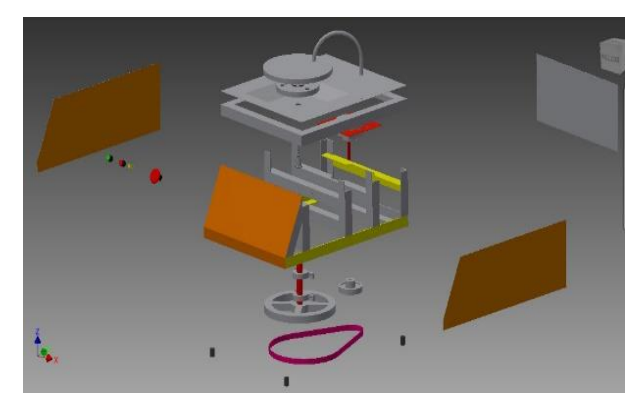

(c)

GAMBAR 2. (a) Rangka mesin poles, (b) 3D mesin poles, dan (c) 3D explode mesin poles. 
Dari gambar 2 dapat terlihat dimensi dari rangka mesin poles pada gambar 2 (a). Sedangkan pada gambar 2 (b) dapat terlihat gambar 3D dari mesin poles. Sedangkan pada gambar 2 (c) dapat terlihat 3D explode mesin poles.

\section{Pembuatan gambar wiring sederhana mesin poles}

Berikut merupakan gambar wiring sederhana kelistrikan.

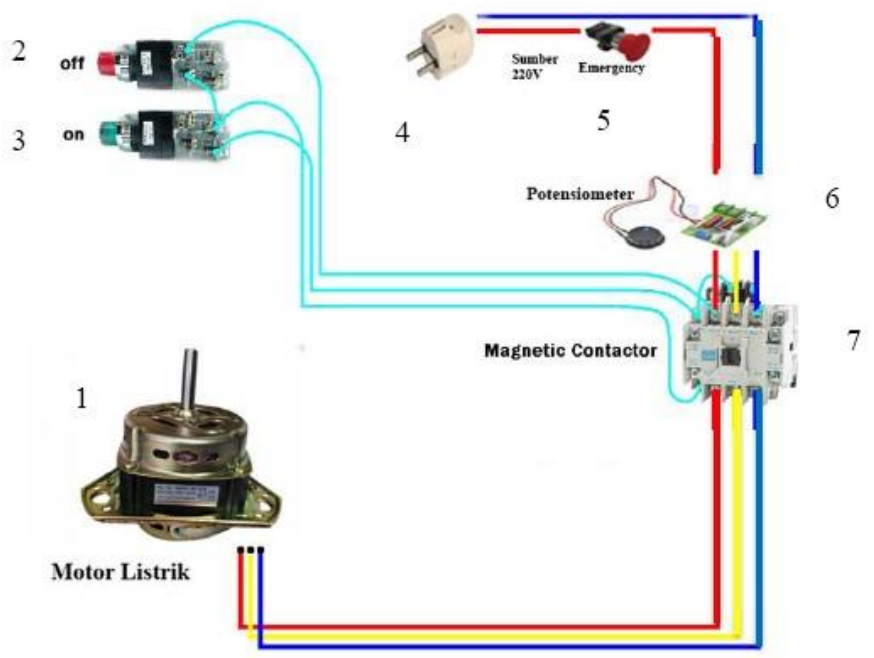

GAMBAR 3. Wiring listrik sederhana

Berdasarkan gambar bisa di lihat bahwa sumber energi berasal dari listrik PLN masuk melalui steker no (4). Ketika menghubungkan steker ke listrik PLN pastikan tombol (push button) no (2), emergency push button no (5) dalam kondisi tidak tertekan dan potensio no (6) dalam posisi berputar penuh ke kiri. Setelah steker terhubung, kemudian pastikan emergency push button no (5) dalam posisi tidak tertekan, dan tombol (push button) no (3) dalam posisi ON. Putar potensio no (6) secara perlahan-lahan ke arah kanan hingga motor listrik no (1) berputar sampai dengan kecepatan yang diinginkan. Jika ada hal yang tidak dinginkan emergency push button no (5) dapat ditekan guna memberhentikan mesin secara mendadak.

\section{Pembuatan Komponen dan Perakitan}

Proses pembuatan mesin poles untuk proses metalografi dapat dilihat pada gambar 4.

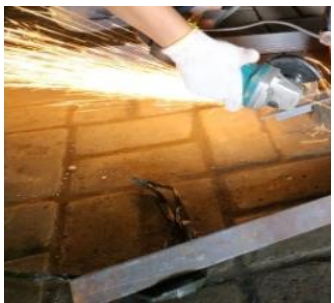

(a)

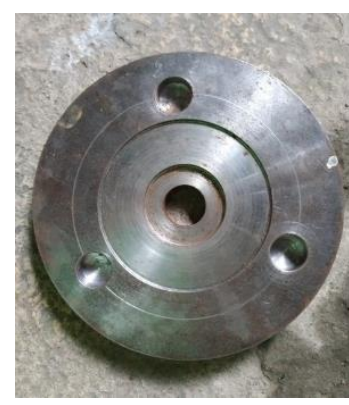

(d)

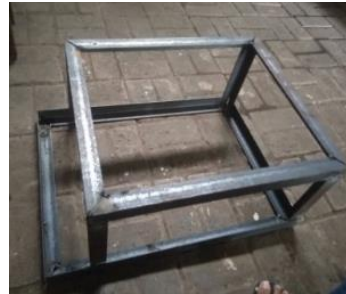

(b)

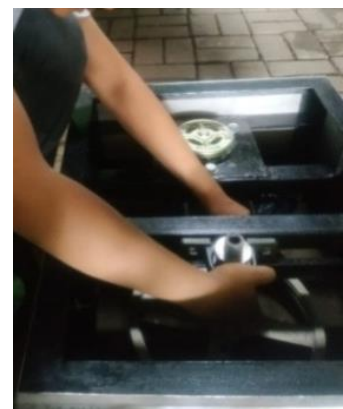

(e)

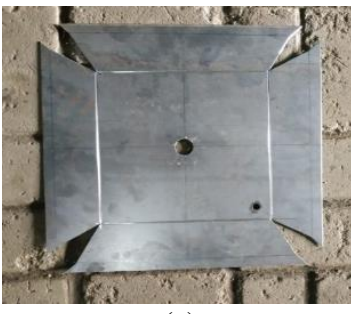

(c)

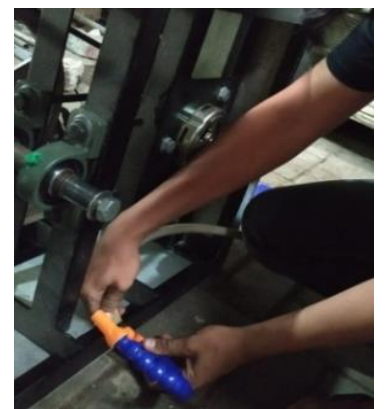

(f) 


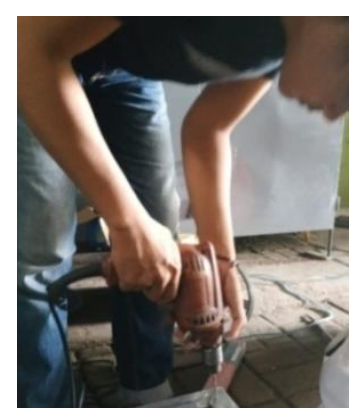

(g)

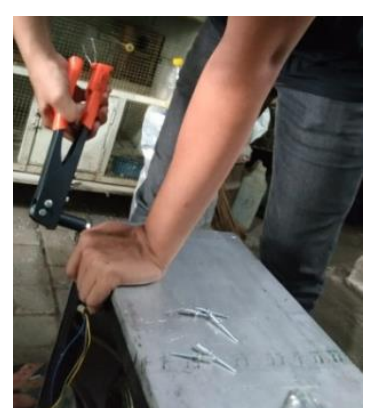

(h)

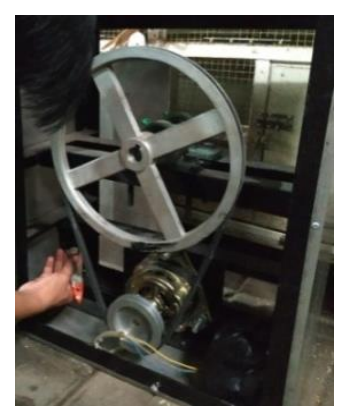

(i)

GAMBAR 4. (a) Pemotongan, (b) Pembuatan rangka, (c) Pelat penutup, (d) Piringan, (e) Pemasangan sistem penggerak, (f) Pemasangan saluran air, (g) Pengeboran rangka, (h) Pemasangan pelat penutup, dan (i) Pengecatan akhir.

Pembuatan mesin poles di mulai dari proses pembuatan rangka. Pada proses pembuatan rangka tahapan pertama yaitu pemotongan besi siku sesuai gambar kerja dan pengelasan. Besi siku yang di gunakan untuk pembuatan alat ini berukuran $40 \times 40 \times 4 \mathrm{~mm}$. Selanjutnya proses pembuatan body. Dalam proses pembuatan body mesin poles ini di awali dengan proses penekukan (bending) pada pelat yang sudah di potong. Penekukan plat adalah proses pengerjaan dengan cara memberikan tekanan pada bagian tertentu sehingga terjadi deformasi plastis pada bagian yang di beri tekanan. Adapun jenis material yang digunakan sebagai body adalah stainless steel. Kemudian selanjutnya proses pembuatan piringan dan poros. Proses pembuatan ini menggunakan proses bubut. Proses bubut adalah proses pemesinan untuk menghasilkan bagian-bagian mesin berbentuk silindris yang di kerjakan dengan menggunakan mesin bubut. Setelah selesai pembuatan poros dan piringan, selanjutnya perakitan sistem penggerak. Pemasangan sistem penggerak ini berfungsi untuk memutar piringan dengan motor penggerak berdaya listrik $135 \mathrm{~W}$. Kemudian selanjutnya pemasangan saluran air untuk pendingin spesimen. Selang yang digunakan adalah selang fleksibel agar mudah di arahkan sesuai keinginan pengguna. Setelah selesai kemudian selanjutnya pemasangan kelistrikan. Pemasangan kelistrikan berdasarkan wiring pada gambar 3. Setelah selesai pemasangan kelistrikan, selanjutnya adalah pemasangan pelat penutup. Pemasangan pelat penutup dengan menggunakan rivet. Sebelum di rivet terlebih dahulu rangka dan body diberi lubang. Dan yang paling terakhir yaitu proses pengecatan. Setelah selesai hasil mesin poles dapat dilihat pada gambar 5 .

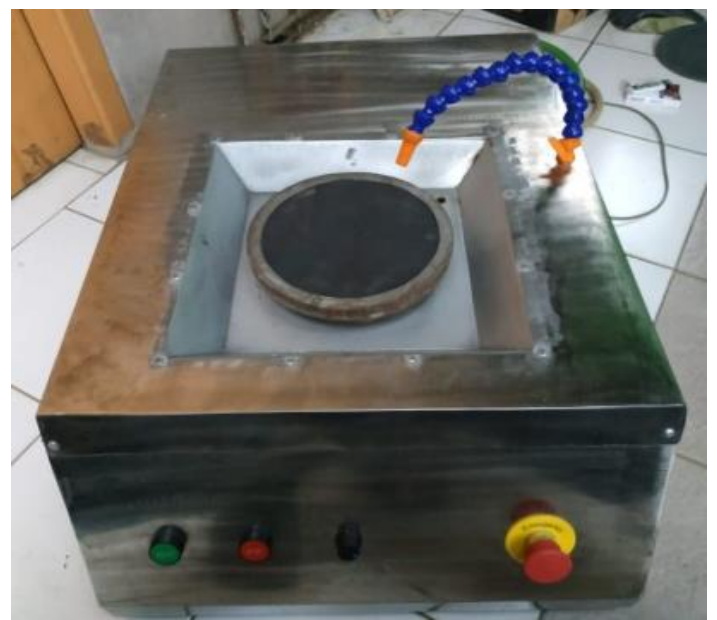

GAMBAR 5. Tampak mesin poles yang telah selesai pembuatannya.

\section{Hasil Pengujian}

Uji coba mesin poles untuk proses metalografi ini menggunakan material alumunim. Sebelum dipoles, sampel dipotong terlebih dahulu menjadi lebih kecil supaya mudah dalam proses pemolesan seperti yang terlihat gambar 6. Setelah dipotong kemudian sampel dipoles dengan menggunakan amplas 240 selama 10 menit dengan. Kemudian selanjutkan sampel di poles kembali dengan menggunakan amplas 1500 selama 5 menit untuk penyelesaian akhir. Pada proses pemolesan ini, sampel maupun amplas terus dialiri air supaya sampel tetap dingin. Berikut gambar hasil dari uji coba proses pemolesan. 


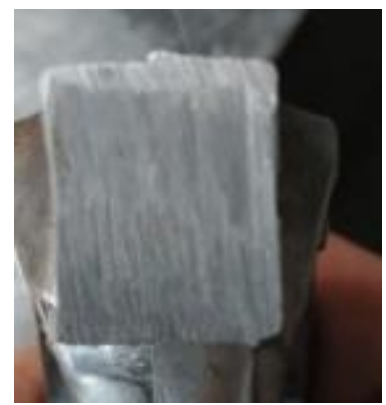

(a)

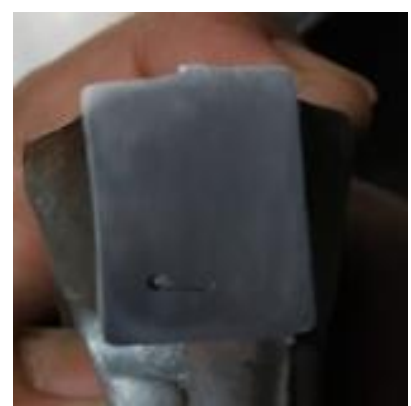

(b)

GAMBAR 5. (a) Sebelum di poles, (b) Sesudah di poles.

\section{KESIMPULAN}

Berdasarkan dari perancangan yang dilakukan maka didapatkan hasil rancangan mesin poles dengan dimensi $500 \times 700 \times 245 \mathrm{~mm}$. Mesin poles ini menggunakan motor AC dengan daya listrik sebesar $135 \mathrm{~W}$ dan tegangan $220 \mathrm{~V}$. Rancangan mesin poles menggunakan sistem pulley untuk mereduksi putaran piringan. Piringan dapat diletakkan amplas (abrasive paper) yang dapat diganti sesuai dengan tingkat kekasarannya. Dari hasil pengujian mesin poles untuk metalografi didapatkan hasil polesan sesuai yang diinginkan.

\section{DAFTAR PUSTAKA}

[1] A. Suhandi and L. Anggraini, "Analisa Struktur Mikro dan Sifat Mekanik Pada Copper-Iron Melalui Proses Mechanical Milling dan Continuous Sintering," J. Mech. Eng. Mechatronics, vol. 2, no. 2, pp. 88-99, 2017.

[2] M. Mandala and E. S. Siradj, "Struktur Mikro Dan Sifat Mekanis Aluminium (AlSi) Pada Proses Pengecoran Menggunakan Cetakan Logam, Cetakan Pasir Dan Cetakan Castable," Poros, vol. 14, no. 2, pp. 88-98, 2016.

[3] S. Mahardika, "Analisa Rekayasa Sifat Mekanik Baja Aisi 4140 Dengan Variasi Suhu Tempering Untuk Meningkatkan Keuletan Dan Kekerasan Material," J. Mekanova Mek. Inov. dan Teknol., vol. 6, no. 1, pp. 64-69, 2020.

[4] Windarta and D. Setiawan, "Optimasi Balancing Putaran Pada Mesin Poles Piringan Ganda Untuk Pengujian Metalografi," Semin. Nas. Sains dan Teknol. 20181 Fak. Tek. Univ. Muhammadiyah Jakarta, vol. 1, pp. 1-8, 2018.

[5] M. I. Almadani and Rudi Siswanto, "Proses Manufaktur Mesin Poles Dan Ampelas Untuk Proses Metalografi," Rotary, vol. 2, no. 1, pp. 15-22, 2020.

[6] G. I. Sukmana and A. H. A. Rasyid, "Redesain Mesin Grinding Dan Polish Semi Otomatis," J. Rekayasa Mesin, vol. 5, no. 1, pp. 51-58, 2018.

[7] V. W. Gandoria, V. V. R. Repi, and A. Wibowo, "Rancang Bangun Pengamat Parameter Cuaca Menggunakan Komunikasi Nir Kabel," J. Ilm. GIGA, vol. 22, no. 1, pp. 14-21, 2019.

[8] A. Supriyadi, V. Vekky, R. Repi, and F. Hidayanti, "Rancang Bangun Sistem Pencampuran Warna Tekstil Otomatis dengan Parameter Volume Fluida pewarna," J. Ilm. GIGA, vol. 21, no. 2, pp. 58-68, 2018.

[9] F. B. Susetyo, I. W. Sugita, B. Basori, M. N. Rifqi, R. Wardiana, and J. Prasetyo, "Rancang Bangun Rak Penetas Telur Otomatis Pada Mesin Tetas Bertenaga Hybrid," J. Ilm. Giga, vol. 23, no. 2, pp. 69-75, 2020.

[10] I. Syinnaqof and D. Riandadari, "Rancang Bangun Mesin Pengaduk Dodol Dan Jenang," J. Rekayasa Mesin, vol. 4, no. 2, pp. 83-88, 2017. 